Letter to the Editor

\title{
Herpes simplex uveitis as a cause of persistent high intraocular pressure after cataract surgery
}

Rachel $I Z$ Goh MBBS, ${ }^{1}$ Yu XIANG GEORGE Kong PhD FRANZCO, ${ }^{1,2}$ Devinder Chauhan MD FRANZCO² and Anne MV Brooks PhD FRANZCO ${ }^{1}$

${ }^{1}$ The Royal Victorian Eye and Ear Hospital, East Melbourne, Victoria, Australia

${ }^{2}$ Centre for Eye Research Australia, East Melbourne, Victoria, Australia

\section{7}

Correspondence: A/Prof Anne Brooks, The Royal Victorian Eye and Ear Hospital, 32

Gisborne Street, East Melbourne, Victoria, Australia 3002

E-Mail: anne.brooks@eyeandear.org.au

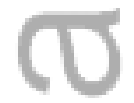

Received 10 March 2016; accepted 18 March 2016

Conflict of interest: None

Funding sources: None

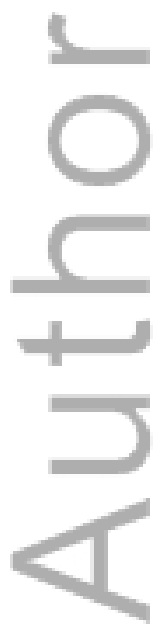

This is the author manuscript accepted for publication and has undergone full peer review but has not been through the copyediting, typesetting, pagination and proofreading process, which may lead to differences between this version and the Version of Record. Please cite this article as doi: $10.1111 /$ ceo.12750

This article is protected by copyright. All rights reserved. 
A 63-year-old man presented in August 2015 with a twelve-day history of persistent high intraocular pressure (IOP) in his right eye (RE) following uncomplicated phacoemulsification surgery. He had been undergoing 3 years of monthly ranibizumab injections for choroidal neovascularisation (CNV) complicating presumed acute multifocal placoid pigment epitheliopathy diagnosed in 1990.

Prior to his cataract surgery he had normal IOP; the surgery was uneventful and peri-operative intracameral cefazolin and subconjunctival dexamethasone were administered. On the first postoperative day (Day 1 ), his right eye IOP was $52 \mathrm{mmHg}$ with a clear cornea and 1+ cells in the anterior chamber and a quiet vitreous. Oral acetazolamide ( $250 \mathrm{mg}$ ) four times daily (QID) and topical latanoprost $0.005 \%$ nocte and were commenced in addition to routine topical dexamethasone $0.1 \%$ QID and chloramphenicol $0.5 \%$ QID. Despite the addition of topical brimonidine $0.2 \%$ twice daily (BD) and laser peripheral iridotomy (PI), the IOP remained $35 \mathrm{mmHg}$ by day 11 when he was referred to our institution.

At this presentation, his best corrected visual acuity was $6 / 6$ in his right eye (left $6 / 36$ ) and his IOPs were $45 \mathrm{mmHg}$ (RE) and $16 \mathrm{mmHg}$ (LE). Both corneas were clear other than right old pigmented keratic precipitates (KP) inferiorly. There was 3+ flare and a few cells in the anterior chamber and the only iris transillumination was related to his bilateral PIs. Gonioscopy showed grade 4 open angles throughout, with some pigmentation but no peripheral anterior synechiae. There was no retained lens material. Both optic discs were medium-sized with cup: disc ratios of 0.5 and there was no vitritis or posterior uveitis.

Retained viscoelastic was unlikely at this stage and the dexamethasone drops were replaced with diclofenac $0.1 \%$ QID to eliminate the possibility of a steroid response. Furthermore, topical brinzolamide $1 \%$-timolol $0.5 \%$ BD was added, the acetazolamide was increased to 500 mg QID and superior 180 degrees of selective laser trabeculoplasty (SLT) was applied; two days later, an inferior 180 degrees of 
SLT was applied, pilocarpine $1 \%$ QID added,and latanoprost $0.005 \%$ changed to bimatoprost $0.03 \%$. As the IOP remained elevated at $42 \mathrm{mmHg}$, pilocarpine $1 \%$ was ceased to exclude a paradoxical response. However, his right IOP continued to rise, reaching $51 \mathrm{mmHg}$, and he was admitted for intravenous mannitol. His anterior chamber remained unchanged with trace cells, and his cornea remained clear.

At this point an urgent fornix-based trabeculectomy was performed, with subconjunctival application of Mitomycin C $0.2 \mathrm{mg} / \mathrm{mL}$ for 2 minutes, and intravitreal bevacizumab to treat his CNV; thin sclera was noted. An intraoperative sample of aqueous humour was positive for an active HSV1 infection on polymerase chain reaction (PCR) testing and a course of oral acyclovir (400mg five times daily) was commenced, in addition to routine topical post-trabeculectomy medications. Over the subsequent 3 weeks, the patient's IOP stabilised with routine posttrabeculectomy care including subconjunctival 5-fluoro-uracil injections and bleb massage. The acyclovir was reduced to a prophylactic dose of $400 \mathrm{mg}$ BD. Following his trabeculectomy surgery, the patient continued his usual regimen of monthly intravitreal ranicizumab. At 2-months post-trabeculectomy, his IOP was $18 \mathrm{mmHg}$ and his BCVA was $6 / 6$.

Surgical trauma has been known to trigger new-onset HSV keratitis and following penetrating keratoplasty, this is a key cause of graft failure ${ }^{1}$. Topical immunosuppressive therapy and post-operative inflammation are proposed triggers for HSV reactivation ${ }^{1}$. Reactivation of HSV keratitis after cataract surgery is rarely reported ${ }^{2,3}$, however, and unlike the three cases reported by Barequet et al in which all patients had early postoperative corneal changes and the appearance of a dendritic epithelial ulcer ${ }^{2}$, or Patel et al's case of a patient presenting at day 5 postsurgery with corneal and eyelid HSV lesions ${ }^{3}$, our case is unique in that there were no corneal or iris signs to point towards a viral cause. Previous retrospective series on HSV anterior uveitis have found that the majority of cases have active keratitis or scarring, or iris abnormalities such as atrophy or distortion, and $50 \%$ have elevated 
$\mathrm{IOP}^{4}$. Clues that may have pointed to a viral cause include the markedly high IOP despite minimal uveitis and the presence of old KP in the eye; however, these may have been related to previous episodes of posterior uveitis.

The trabeculectomy surgery afforded an opportunity to simultaneously obtain an aqueous sample. Aqueous humour PCR confirmation of HSV infection prior to commencing antiviral medication is advised in order to guide treatment of the acute episode and subsequent conditions that may occur such as retinitis, even if surgery is not indicated.

In conclusion, we suggest that reactivation of HSV uveitis should be considered in cases of unexplained persistent elevated IOP following uncomplicated intraocular surgery and any suspicion should be confirmed with aqueous sampling. 


\section{REFERENCES}

1. Beyer CF, Hill J M, Byrd TJ, Kaufman HE. Herpes simplex dendritic keratitis after keratoplasty. Am J Ophthalmol 1991; 112: 355-6.

2. Barequet IS, Wasserzug Y. Herpes simplex keratitis after cataract surgery. Cornea 2007; 26: 615-7.

3. Patel NN, Teng CC, Sperber LT, Dodick JM. New-onset herpes simplex virus " keratitis after cataract surgery. Cornea 2009; 28: 108-10.

4. Tugal-Tutkun I, Otuk-Yasar B, Altinkurt E. Clinical features and prognosis of herpetic anterior uveitis: a retrospective study of 111 cases. Int Ophthalmol 2010; 30: 559-65.

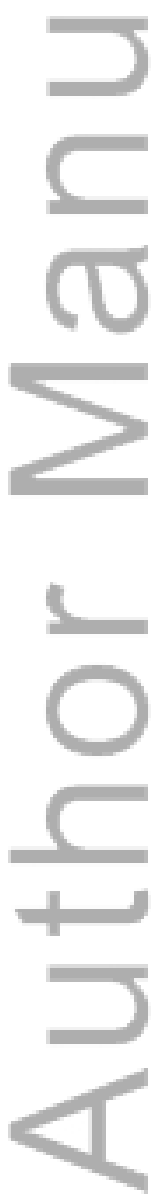




\section{University Library}

\section{- M M N E R VA A gateway to Melbourne's research publications}

Minerva Access is the Institutional Repository of The University of Melbourne

Author/s:

Goh, RLZ;Kong, YXG;Chauhan, D;Brooks, AMV

Title:

Herpes simplex uveitis as a cause of persistent high intraocular pressure after cataract surgery

Date:

2016-11-01

Citation:

Goh, R. L. Z., Kong, Y. X. G., Chauhan, D. \& Brooks, A. M. V. (2016). Herpes simplex uveitis as a cause of persistent high intraocular pressure after cataract surgery. CLINICAL AND EXPERIMENTAL OPHTHALMOLOGY, 44 (8), pp.726-727. https://doi.org/10.1111/ceo.12750.

Persistent Link:

http://hdl.handle.net/11343/291272 